\title{
Niacin (nicotinic acid) in non-physiological doses causes hyperhomocysteineaemia in Sprague-Dawley rats
}

\author{
Tapan K. Basu*, Neelam Makhani and Gary Sedgwick \\ Department of Agricultural, Food and Nutritional Science, University of Alberta, Edmonton, Alberta, T6G 2P5 Canada
}

(Received 22 September 2000 - Revised 17 July 2001 - Accepted 6 August 2001)

\begin{abstract}
Niacin (nicotinic acid) in its non-physiological dose level is known to be an effective lipidlowering agent; its potential risk as a therapeutic agent, however, has not been critically considered. Since niacin is excreted predominantly as methylated pyridones, requiring methionine as a methyl donor, the present study was undertaken to examine whether metabolism of the amino acid is altered in the presence of large doses of niacin. Male Sprague-Dawley rats were given a nutritionally adequate, semi-synthetic diet containing niacin at a level of either 400 or $1000 \mathrm{mg} / \mathrm{kg}$ diet (compared to $30 \mathrm{mg} / \mathrm{kg}$ in the control diet) for up to 3 months. Supplementation with niacin $(1000 \mathrm{mg} / \mathrm{kg}$ diet $)$ for 3 months resulted in a significant increase in plasma and urinary total homocysteine levels; this increase was further accentuated in the presence of a high methionine diet. The hyperhomocysteineaemia was accompanied by a significant decrease in plasma concentrations of vitamins $\mathrm{B}_{6}$ and $\mathrm{B}_{12}$, which are cofactors for the metabolism of homocysteine. The homocysteine-raising action of niacin, in particular, has an important toxicological implication, as hyperhomocysteineaemia is considered to be an independent risk factor for arterial occlusive disease. The niacin-associated change in homocysteine status may be an important limiting factor in the use of this vitamin as a lipid-lowering agent.
\end{abstract}

\section{Niacin: Homocysteine: Methionine: Cysteine: B-vitamins}

Niacin (nicotinic acid; vitamin $\mathrm{B}_{3}$ ) in large doses $(>2.0 \mathrm{~g} / \mathrm{d})$ has been known to be effective in the treatment of hyperlipidaemia (Goldberg, 1998; Guyton, 1998; Knopp, 1998). The potential risk of long-term usage of large doses of niacin has not been critically considered. Its only consistent deleterious effect in high doses has hitherto been cutaneous flushing and/or itching (McKenney et al. 1994; Capuzzi et al. 1998), which are thought to be caused by prostaglandin-mediated vasodilatation (Keenan et al. 1991).

Niacin is excreted as methylated pyridones (Shibata \& Matsuo, 1989). By way of these metabolites, methylation occurs through a simple methyl transfer reaction, in which S-adenosylmethionine is the methyl donor. Niacin is a water-soluble vitamin and, therefore, is not stored in the body beyond its tissue saturation level. Since niacin excretion is dependent upon the availability of methionine, an intake of niacin in large amounts may affect the metabolism of this essential amino acid. Such an effect has been demonstrated in a recent study (Basu \& Mann, 1997), as evidenced by niacin-associated increases in plasma and urinary levels of homocysteine in rats. This is an important observation, since homocysteine is thought to be an independent risk factor for arterial occlusive disease (Verhoef et al. 1997; Jacobsen, 1998; Welch \& Loscalzo, 1998; Finkelstein, 2000). The study, however, measured the free homocysteine fraction, which accounts for only a small percentage of the total homocysteine (Mansoor et al. 1992). More than $80 \%$ of homocysteine in blood is bound to protein by a disulfide linkage, and during storage there may be redistribution of thiols resulting in an increase in the protein-bound fraction at the expense of the free form. It is, therefore, important to determine whether niacin treatment modifies the total homocysteine status.

Using Sprague-Dawley rats the present study was undertaken to investigate the modifying effect of nonphysiological dose levels of niacin on methionine metabolism and its consequence on total homocysteine status. Methionine synthesis requires 5-methyl tetrahydrofolate as a methyl donor and vitamin $\mathrm{B}_{12}$ as a cofactor; furthermore, its degradation to cysteine is catalysed by

Abbreviation: PLP, pyridoxal-5'phosphate.

* Corresponding author: Dr Tapan K. Basu, fax +1 780492 9130, email tbasu@afns.ualberta.ca 
cystathionase, for which vitamin $\mathrm{B}_{6}$ is the cofactor (Stipanuk, 1986). To elucidate the biochemical basis of the presumed hyperhomocysteineaemic effect of niacin, the biochemical status of vitamins $\mathrm{B}_{12}$ and $\mathrm{B}_{6}$, as well as folate, was measured in niacin-treated rats.

\section{Materials and methods}

\section{Animals and diets}

Male Sprague-Dawley rats (weighing 150-200g) were used throughout the study. They were individually housed in stainless steel metabolic cages in a well-ventilated room maintained at approximately $21^{\circ} \mathrm{C}$ and were on a $12 \mathrm{~h}$ lightdark cycle. All animals were fed a pellet diet (Laboratory Rodent Diet no. 5001; PMI Feeds Inc., Richmond, Ontario) for 1 week before being fed an experimental semi-synthetic diet (Table 1). The study protocol was approved by the Animal Welfare Committee of the University of Alberta.

After a run-in period (1 week) the rats were randomly divided into five groups of six each. Group 1 animals were fed a semi-synthetic diet containing physiological levels of niacin (Table 1) and were used as controls (diet A). Groups 2 and 3 were fed the control diet containing niacin at two additional dose levels: $400 \mathrm{mg}$ (diet B) and $1000 \mathrm{mg}$ (diet $\mathrm{C}) / \mathrm{kg}$ diet. Groups 4 and 5 were fed the semi-synthetic diet supplemented with $10 \mathrm{~g}$ methionine/kg diet, either alone (diet D) or in combination with $1000 \mathrm{mg}$ niacin $/ \mathrm{kg}$ diet (diet E). The dose levels of niacin are close to those consumed by humans on a body weight basis. This calculation is based upon the fact that the niacin dose level, necessary to achieve its lipid-lowering effect in humans, is usually in the range of $2-6 \mathrm{~g} / \mathrm{d}$ (Guyton, 1998). The rats used in the present study weighed $150-200 \mathrm{~g}$ and they ate approximately $20 \mathrm{~g}$ food/d. All animals had free access to water and their respective diets for 1-3 months.

Table 1. Composition of the semi-synthetic diet fed to Sprague-Dawley rats

\begin{tabular}{|c|c|}
\hline Ingredient* & $\mathrm{g} / \mathrm{kg}$ \\
\hline asein & 200 \\
\hline laize starch & 648 \\
\hline laize oil & 60 \\
\hline itamin mix† & 10 \\
\hline lineral mixł & 30 \\
\hline ellulose powder & 50 \\
\hline L-Methionine & 2 \\
\hline \multicolumn{2}{|c|}{ 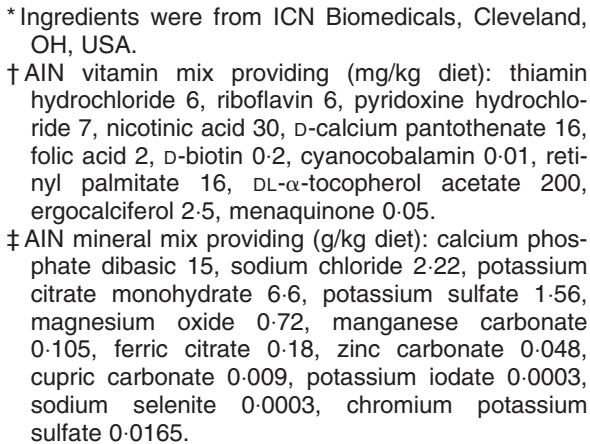 } \\
\hline
\end{tabular}

Body weight and daily food intake of all rats were recorded at weekly intervals throughout the study period. Urine samples $(24 \mathrm{~h})$ were collected twice from each rat towards the end of each experiment; their pooled volumes were recorded. Rats were killed in a $\mathrm{CO}_{2}$ chamber following overnight food deprivation. Blood samples were collected through cardiac puncture in heparinized tubes, and plasma was separated by centrifugation $\left(2800 \mathrm{~g}\right.$ for $10 \mathrm{~min}$ at $\left.-4^{\circ} \mathrm{C}\right)$ within half an hour of collection. The livers were removed and weighed. The separated plasma and aliquots of pooled urine samples were stored at $-40^{\circ} \mathrm{C}$ for a maximum period of 3 weeks before analyses were performed.

\section{Amino acid analysis}

Total methionine, homocysteine and cysteine levels in plasma and urine were determined using the method of Sedgwick et al. (1991), but following a modification. To $100 \mu \mathrm{l}$ plasma or urine or standard, $50 \mu \mathrm{l}$ of $100 \mathrm{nmol} / \mathrm{ml}$ internal standard comprising $\mathrm{L}-\alpha$-amino- $\beta$-guadinopropionic acid and $25 \mu \mathrm{l} 10 \%$ (v/v) tributylphosphine in dimethylformamide were added. A volume of $100 \mu \mathrm{l}$ cold $10 \%$ TCA was added to all tubes, which were then vortexed and centrifuged at $3000 \mathrm{rpm}$ for $15 \mathrm{~min}$. To $150 \mu \mathrm{l}$ supernatant, $100 \mu \mathrm{l}$ performic acid (formic acid:hydrogen peroxide, 9:1) was added and tubes were left overnight at $4^{\circ} \mathrm{C}$. On the following day, $50 \mu 10.3362 \mathrm{~g} / \mathrm{ml}$ sodium metasulfite was added to all tubes and mixed vigorously. Samples were vacuum dried and the precipitate was reconstituted with $600 \mu \mathrm{l}$ saturated potassium tetraborate. In chromatographic vials, $300 \mu$ l sample and $100 \mu l$ water were added ( $\mathrm{pH}$ 9.5). Samples were analysed using $o$-phthaldialdehyde as a pre-column derivatizing agent. The quantification of amino acids was accomplished by the use of a Varian 5000 HPLC and a Varian fluorichrome detector (Columbia, MD, USA) at excitation $340 \mathrm{~nm}$ and emission $450 \mathrm{~nm}$. Urine and plasma samples were mixed 1:1 with the fluraldehyde reagent prior to injection. The mixed sample $(25 \mu \mathrm{l})$ was injected onto a supelcosil $3 \mu \mathrm{m}$ LC 18 reverse phase column $(4.6 \times 150 \mathrm{~mm}$; supelco $)$. Chromatographic peaks were recorded and integrated using the Shimadzu Ezchrom Chromatography Data System (Shimadzu, Kyoto, Japan).

\section{Vitamin analysis}

Plasma vitamin $\mathrm{B}_{12}$ and folate were determined by using the commercially available 'dualcount solid phase boil assay kit' (Inter Medico, Markham, Ontario). The vitamins present in the sample were released from the carrier proteins by incubation at $100^{\circ} \mathrm{C}$ in the presence of dithiothreitol and potassium cyanide. Addition of purified hog intrinsic factor and purified $\beta$-lactoglobulin served as the binders for vitamin $B_{12}$ and folate, respectively. The unlabelled vitamin $\mathrm{B}_{12}$ or folate competes with its labelled species for the limited number of available binding sites on its specific binder, thus reducing the amount of labelled vitamin $\mathrm{B}_{12}$ or folate bound. After an adequate incubation period, isolation of the bound fraction is achieved by centrifuging and decanting. Counts in the precipitate are then converted, by comparison with the calibration curve, 
into vitamin $\mathrm{B}_{12}$ and folate concentrations. The level of radioactivity bound is inversely related to concentration in the sample or standard.

Plasma pyridoxal-5'-phosphate (PLP) was determined by using a commercially available radioassay kit (Buhlmann Laboratories AG, Switzerland), as a modification of the method described by Shin-Buckring et al. (1981). The principle of the assay involves the decarboxylation of $\mathrm{H}$-tyrosine by the vitamin $\mathrm{B}_{6}$-dependent tyrosine apodecarboxylase to H-tyramine. The excess of H-tyramine remains in the aqueous phase and is measured by means of a liquid scintillation counter.

\section{Statistical analysis}

Means and standard error of the means were determined for all groups of rats. Data were analysed by using one-way ANOVA. Significant effects were determined by using the Student $t$ and multiple comparison tests (Steel \& Torrie 1953). In the present study the level of significance considered was set at 0.05.

\section{Results}

Feeding rats a semi-synthetic diet containing $400 \mathrm{mg}$ niacin/kg diet (diet B) for 1 month did not affect food intake, growth rate or liver weight (data not shown). They remained unaffected even when the diet was fed for 3 months (Table 2). However, feeding for this period of time a diet containing $1000 \mathrm{mg}$ niacin $/ \mathrm{kg} \operatorname{diet}(\operatorname{diet} \mathrm{C}$ ) resulted in a significant increase in both body weight gain and liver weight, but not the daily food intake. Similarly, the plasma and urinary levels of total methionine, homocysteine and cysteine remained unchanged when diet B was fed for 1 month (results not shown). Feeding this diet for 3 months, on the other hand, resulted in significant increases in plasma levels of the amino acids; their levels in urine were also elevated but a significant level was attained only for methionine (Table 3). The magnitude of increase in both plasma and urinary levels of homocysteine and cysteine, in particular, was exacerbated when the supplemental amount of niacin was increased to $1000 \mathrm{mg} / \mathrm{kg}$ diet.

Rats fed for 3 months with a semi-synthetic diet loaded with methionine $(10 \mathrm{~g} / \mathrm{kg})$ plus niacin $(1000 \mathrm{mg} / \mathrm{kg})$ showed a significant decrease in homocysteine and no changes in cysteine and methionine levels in the plasma, compared

Table 2. Effect of feeding a diet ${ }^{*}$ supplemented with niacin for 3 months on food intake and growth of Sprague-Dawley rats

(Mean values with their standard errors for six rats)

\begin{tabular}{|c|c|c|c|c|c|c|}
\hline & \multicolumn{2}{|c|}{ Control* $^{*}$} & \multicolumn{2}{|c|}{$\begin{array}{c}\text { Niacin } \\
(400 \mathrm{mg} / \mathrm{kg})\end{array}$} & \multicolumn{2}{|c|}{$\begin{array}{c}\text { Niacin } \\
(1000 \mathrm{mg} / \mathrm{kg})\end{array}$} \\
\hline & Mean & SE & Mean & SE & Mean & SE \\
\hline $\begin{array}{l}\text { Food intake }(\mathrm{g} / \mathrm{d}) \\
\text { Body wt gain }(\mathrm{g})\end{array}$ & $\begin{array}{r}19 \cdot 9^{a} \\
326 \cdot 8^{a}\end{array}$ & $\begin{array}{l}0.5 \\
7.8\end{array}$ & $\begin{array}{l}20.02^{a} \\
330 \cdot 0^{a}\end{array}$ & $\begin{array}{l}0.4 \\
5 \cdot 7\end{array}$ & $\begin{array}{r}22 \cdot 6^{a} \\
416 \cdot 0^{b}\end{array}$ & $\begin{array}{r}1 \cdot 0 \\
21 \cdot 1\end{array}$ \\
\hline Liver wt $(\mathrm{g})$ & $12 \cdot 7^{a}$ & 0.3 & $13 \cdot 9^{a}$ & 0.2 & $18 \cdot 0^{\mathrm{b}}$ & 1.3 \\
\hline
\end{tabular}

\footnotetext{
${ }^{a, b}$ Values within a row not sharing a common superscript letter were significantly different $(P<0.05)$.

${ }^{*}$ For details of the diets, see Table 1.
}

with those fed a diet loaded with only methionine (Table 4). However, urinary concentrations of these amino acids were all significantly higher in the presence of niacin.

Plasma vitamin $\mathrm{B}_{12}$, folate or PLP levels were unaffected (results not shown) by feeding rats a semi-synthetic diet containing $400 \mathrm{mg}$ niacin/ $\mathrm{kg}$ diet for 1 month. The same level of niacin supplementation for 3 months, however, caused a significant reduction in plasma vitamin $B_{12}$ but not PLP or folate (Table 5). The plasma levels of both vitamin $\mathrm{B}_{12}$ and PLP were significantly decreased when dietary niacin level was increased to $1000 \mathrm{mg} / \mathrm{kg}$ diet (diet C). Unlike these vitamins the plasma folate levels remained unchanged in rats fed niacin at all dose levels. The responses of the B-vitamins to niacin were similar in rats fed a methionine-rich diet (Table 5).

\section{Discussion}

Supplementing a diet containing $1000 \mathrm{mg}$ niacin/ $\mathrm{kg}$ diet to male Sprague-Dawley rats for 3 months resulted in a significant increase in both plasma and urinary total homocysteine levels. The increase, especially, in the urine, was further accentuated by loading the diet with methionine. These results are in agreement with a previous study (Basu \& Mann, 1997), which demonstrated a niacinassociated increase in plasma free homocysteine level. This agreement is of particular interest since the earlier study measured only free homocysteine, which comprises only a small portion of total homocysteine. The fact that the present study measured total homocysteine status, and that the results obtained are in parallel with those of the previous study, suggests that niacin at pharmacological doses is potentially hyperhomocysteineaemic.

In the present study the addition of supplemental niacin to a diet resulted in a marked decrease in the levels of plasma PLP. The niacin-associated decline in plasma PLP was in parallel with an increase in plasma homocysteine. These results imply that the breakdown of homocysteine to cysteine is affected by the presence of supplemental niacin. As vitamin $B_{6}$ in its coenzyme form of PLP is involved in the trans-sulfuration of homocysteine, niacin at pharmacological doses may affect the biochemical status of this cofactor. In the presence of excess methionine the trans-sulfuration pathway is generally favoured by upregulation of its rate-limiting enzyme, cystathionine $\beta$-synthase (Finkelstein \& Martin, 1986). The cysteine that is formed from homocysteine is either oxidized to taurine and inorganic sulfates or excreted in the urine. This means that dietary methionine load stresses the metabolic pathway responsible for the irreversible degradation of homocysteine to cysteine. It is noteworthy that niacin in the presence of excess dietary methionine lowered the level of plasma homocysteine, while its urinary concentration along with cysteine was markedly increased. This further suggests that excess niacin may affect the trans-sulfuration of homocysteine to cysteine.

Homocysteine can be recycled to methionine. Methionine synthase is a rate-limiting enzyme for this remethylation reaction for which vitamin $B_{12}$ and folate serve as cofactor or co-substrate, respectively. The plasma vitamin $\mathrm{B}_{12}$, but not folate, was markedly reduced in the presence of niacin. 
Table 3. Effect of a diet* supplemented with niacin for 3 months on plasma and urinary total methionine, homocysteine and cysteine levels in Sprague-Dawley rats

(Mean values with their standard errors for six rats)

\begin{tabular}{|c|c|c|c|c|c|c|}
\hline & \multicolumn{2}{|c|}{ Control* $^{*}$} & \multicolumn{2}{|c|}{$\begin{array}{c}\text { Niacin } \\
(400 \mathrm{mg} / \mathrm{kg})\end{array}$} & \multicolumn{2}{|c|}{$\begin{array}{c}\text { Niacin } \\
(1000 \mathrm{mg} / \mathrm{kg})\end{array}$} \\
\hline & Mean & SE & Mean & SE & Mean & SE \\
\hline \multicolumn{7}{|l|}{ Plasma (nmol/ml) } \\
\hline Methionine & $27 \cdot 25^{\mathrm{a}}$ & 0.24 & $42 \cdot 17^{b}$ & 1.35 & $38 \cdot 61^{b}$ & 0.74 \\
\hline Homocysteine & $3.58^{a}$ & 0.17 & $7 \cdot 39^{b}$ & 0.44 & $9.52^{c}$ & 0.56 \\
\hline Cysteine & $247 \cdot 00^{a}$ & $10 \cdot 8$ & $300 \cdot 90^{\mathrm{b}}$ & $7 \cdot 6$ & $415 \cdot 6^{\mathrm{C}}$ & 11.0 \\
\hline \multicolumn{7}{|l|}{ Urine (nmol/24h) } \\
\hline Methionine & $1993^{a}$ & 433 & $2077^{b}$ & 410 & $3869^{c}$ & 421 \\
\hline Homocysteine & $242^{a}$ & 15 & $275^{a}$ & 25 & $451^{\mathrm{c}}$ & 64 \\
\hline Cysteine & $950^{\mathrm{a}}$ & 78 & $1137^{\mathrm{a}}$ & 103 & $1791^{\mathrm{c}}$ & 229 \\
\hline
\end{tabular}

${ }^{a, b}$ Values within a row not sharing a common superscript letter were significantly different $(P<0.05)$.

${ }^{*}$ For details of the diets, see Table 1.

Table 4. Effect of feeding a diet ${ }^{\star}$ supplemented with methionine $(10 \mathrm{~g} / \mathrm{kg})$ and niacin $(1000 \mathrm{mg} / \mathrm{kg})$ for 3 months on plasma and urinary total methionine, homocysteine and cysteine levels in Sprague-Dawley rats

(Mean values with their standard errors for six rats)

\begin{tabular}{|c|c|c|c|c|c|}
\hline & \multicolumn{2}{|c|}{ Methione } & \multicolumn{2}{|c|}{$\begin{array}{l}\text { Methionine plus } \\
\text { niacin }\end{array}$} & \multirow{2}{*}{$\begin{array}{l}\text { Student's } t \text { test } \\
\quad(P \text { value })\end{array}$} \\
\hline & Mean & SE & Mean & SE & \\
\hline \multicolumn{6}{|l|}{ Plasma (nmol/ml) } \\
\hline Methionine & $40 \cdot 6$ & 1.3 & $43 \cdot 6$ & $2 \cdot 3$ & NS \\
\hline Homocysteine & 7.5 & 0.4 & $5 \cdot 6$ & 0.5 & $<0.05$ \\
\hline Cysteine & 394 & 8 & 360 & 12 & NS \\
\hline \multicolumn{6}{|l|}{ Urine (nmol/24h) } \\
\hline Methionine & 3632 & 1344 & 16483 & 4273 & $<0.001$ \\
\hline Homocysteine & 443 & 55 & 806 & 127 & $<0.001$ \\
\hline Cysteine & 1030 & 146 & 2015 & 195 & $<0.001$ \\
\hline
\end{tabular}

${ }^{*}$ For details of the diets, see Table 1.

Table 5. Effect of niacin supplementation for 3 months on the plasma levels of B-vitamins in Sprague-Dawley rats

(Mean values with their standard errors for six rats)

\begin{tabular}{|c|c|c|c|c|c|c|}
\hline & \multicolumn{2}{|c|}{$\begin{array}{l}\text { Vitamin } \mathrm{B}_{12} \\
(\mathrm{pmol} / \mathrm{l})\end{array}$} & \multicolumn{2}{|c|}{$\begin{array}{l}\text { Folate } \\
(\mathrm{nmol} / \mathrm{l})\end{array}$} & \multicolumn{2}{|c|}{$\begin{array}{c}\text { PLP } \\
(\mathrm{nmol} / \mathrm{l})\end{array}$} \\
\hline & Mean & SE & Mean & SE & Mean & SE \\
\hline Control & $450 \cdot 8^{a}$ & $21 \cdot 1$ & $150 \cdot 6^{a}$ & 4.2 & $425 \cdot 6^{\mathrm{a}}$ & $9 \cdot 2$ \\
\hline Niacin $(400 \mathrm{mg})^{\star}$ & $375 \cdot 9^{b}$ & 28.6 & $148 \cdot 9^{\mathrm{a}}$ & $6 \cdot 1$ & $418 \cdot 7^{\mathrm{a}}$ & $11 \cdot 1$ \\
\hline Niacin $(1000 \mathrm{mg})^{*}$ & $370 \cdot 4^{b}$ & $17 \cdot 1$ & $148 \cdot 2^{a}$ & 4.6 & $370 \cdot 1^{b}$ & $10 \cdot 2$ \\
\hline Methionine $(10 \mathrm{~g})^{\star}$ & $409 \cdot 4^{\mathrm{a}}$ & 31.6 & $149 \cdot 8^{a}$ & $4 \cdot 1$ & $441 \cdot 4^{\mathrm{a}}$ & $11 \cdot 8$ \\
\hline Methionine $(10 \mathrm{~g})+\operatorname{niacin}(1000 \mathrm{mg})^{\star}$ & $327 \cdot 6^{\mathrm{b}}$ & $10 \cdot 8$ & $142 \cdot 6^{\mathrm{a}}$ & $6 \cdot 6$ & $389 \cdot 6^{\mathrm{b}}$ & $14 \cdot 1$ \\
\hline
\end{tabular}

a,b Mean values within a column not sharing a common superscript letter were significantly different $(P<0.05)$. PLP, pyridoxal-5'-phosphate.

${ }^{*}$ Per kg diet.

Adequate vitamin $\mathrm{B}_{12}$ must be present for the activity of methionine synthase, the enzyme that removes the methyl group from 5-methyl tetrahydrofolate and delivers it to homocysteine (Finkelstein, 1998). The latter is then converted to methionine and consequently the free tetrahydrofolate is regenerated. Since 5-methyl tetrahydrofolate may return to the body's folate only via a vitamin
$\mathrm{B}_{12}$-dependent step, a deficiency of vitamin $\mathrm{B}_{12}$ traps body folate in its methylated form. It is plausible that the niacininduced deficiency of vitamin $\mathrm{B}_{12}$ may have resulted in the 'trapping' of folate, which would maintain normal plasma folate levels. This may explain why folate levels were not affected by niacin.

The metabolic fate of homocysteine is linked to vitamin 
$\mathrm{B}_{12}$, folate and vitamin $\mathrm{B}_{6}$. Results from the present study suggest that niacin in pharmacological doses may affect the status of vitamins $\mathrm{B}_{12}$ and $\mathrm{B}_{6}$. Hyperhomocysteineaemia may be a consequence of their metabolic interactions.

In recent years, there has been a substantial amount of research leading to the development of the "homocysteine theory of atherosclerosis'. Both retrospective and prospective studies have shown that elevated plasma total homocysteine is an independent risk factor for occlusive disease in the coronary, cerebrovascular and peripheral vessels and for arterial and venous thrombosis (Boushey et al. 1995; DenHeijer et al. 1996; D’Angelo et al. 1997; Refsum et al. 1998).

It appears from the present study that the hypolipidaemic action of niacin could be potentially negated by its hyperhomocysteineaemic effect. It is important that clinical studies are carried out in order to determine whether these results could be extrapolated to humans. Future studies should also examine whether concurrent supplementation of niacin with vitamins $\mathrm{B}_{6}$ and $\mathrm{B}_{12}$ counteract the niacininduced hyperhomocysteineaemia without affecting its hypolipidaemic action.

\section{Acknowledgements}

This research was supported by the Natural Sciences and Engineering Research Council of Canada.

\section{References}

Basu TK \& Mann S (1997) Vitamin $B_{6}$ normalizes the altered sulfur amino acid status of rats fed diets containing pharmacological levels of niacin without reducing niacin's hypolipidemic effects. Journal of Nutrition 127, 117-121.

Boushey CJ, Beresford SAA, Omenn GS \& Motulsky AG (1995) A quantitative assessment of plasma homocysteine as a risk factor for vascular disease: probable benefits of increasing folic acid intake. Journal of the American Medical Association 274, 997-1092.

Capuzzi DM, Guyton JR, Morgan JM, Goldberg AC, Kreisberg RA, Brusco OA \& Brody J (1998) Efficacy and safety of an extended-release niacin (Niaspan): A long-term study. American Journal of Cardiology 82, 74U-81U.

D’Angelo A, Mazzola G, Crippa L, Fermo I \& D'Angeloo SV (1997) Hyperhomocysteinemia and venous thromboembolic disease. Haematologica 82, 211-219.

DenHeijer M, Koster T \& Blom HJ (1996) Hyperhomocysteinemia as a risk factor for deep-vein thrombosis. New England Journal of Medicine 334, 759-762.

Finkelstein JD (1998) The metabolism of homocysteine: pathways and regulation. European Journal of Pediatrics 157, S40-S44.
Finkelstein JD (2000) Homocysteine: A history in progress. Nutrition Reviews 58, 193-204.

Finkelstein JD \& Martin JJ (1986) Methionine metabolism in mammals. Journal of Biological Chemistry 261, 1582-1587.

Goldberg AC (1998) Clinical trial experience with extendedrelease niacin (Niaspan): dose-escalation study. American Journal of Cardiology 82, 35U-38U.

Guyton JR (1998) Effect of niacin on cardiovascular disease. American Journal of Cardiology 82, 18U-23U.

Jacobsen DW (1998) Homocysteine and vitamins in cardiovascular disease. Clinical Chemistry 44, 1833-1843.

Keenan JM, Fontaine PL, Wenz JB, Huang ZQ \& Ripsin CM (1991) A randomized controlled trial of wax-matrix sustained release niacin in hypercholesterolemia. Archives of Internal Medicine 151, 1424-1432.

Knopp RH (1998) Clinical profiles of plain versus sustainedrelease niacin and the physiologic rationale for nighttime dosing. Americal Journal of Cardiology 82, 35U-38U.

McKenney JM, Proctor JD, Harris S \& Chinchili VM (1994) A comparison of the efficacy and toxic effects of sustained- versus immediate-release niacin in hypercholesterolemic patients. Journal of American Medical Association 271, 672-676.

Mansoor MA, Svardal AM \& Ueland PM (1992) Determination of the in vivo redox status of cysteine, cysteineylglycine, homocysteine and glutathione in human plasma. Analytical Biochemistry 200, 218-229.

Refsum H, Ueland PM, Nygard O \& Vollset SE (1998) Homocysteine and cardiovascular disease. Annual Review of Medicine 49, 31-62.

Sedgwick GW, Fenton TW \& Thompson JR (1991) Effect of protein precipitating agents on the recovery of plasma free amino acids. Canadian Journal of Animal Science 71, 953-957.

Shibata K \& Matsuo H (1989) Correlation between niacin equivalent intake and urinary excretion of its metabolites: $N^{1}$-methylnicotinamide $N^{1}$-methyl-2-pyridone-5-carboxamide, and $N^{1}$-methyl-4-pyridone-3-carboxamide, in humans consuming a self-selected food. American Journal of Clinical Nutrition 50, 114-119.

Shin-Buckring Y, Rasshofer R \& Endres W (1981) A new enzymatic method for pyridoxal-5'-phosphate determination. Journal of Inherited Metabolic Disease 4, 123-124.

Steel RGD \& Torrie JH (1953) Principles and procedures of statistics: A Biometrical Approach, pp. 67-119. New York, NY: McGraw-Hill.

Stipanuk MH (1986) Metabolism of sulfur-containing amino acids. Annual Review of Nutrition 6, 179-209.

Verhoef P, Henneckens C, Allen R, Stabler S, Willet W \& Stampfer M (1997) Plasma total homocysteine and risk of angina pectoris with subsequent coronary bypass artery surgery. American Journal of Cardiology 79, 799-801.

Welch G \& Loscalzo J (1998) Homocysteine and atherosclerosis. New England Journal of Medicine 338, 1042-1049. 